\title{
Celebration of seasonally based holidays and festivals in Japan: a study in cultural adaptation
}

\author{
Steven L. Renshaw \\ Kanda University of International Studies, 1-4-1 Wakaba, Mihama Ku, 261-0014 Chiba, Japan \\ email: stever@gol.com
}

\begin{abstract}
The way in which Japan adopted methods and practices related to celebrations of seasonally based holidays and festivals provides an interesting study in how one culture may incorporate and modify the astronomically related practices of another. This article explores this process by looking at: (1) astronomical bases of seasonal celebration in Japan, (2) Japanese values and adaptations of imported icons and practices, (3) changes in celebratory practice due to adoption of 'Western' methods, and (4) observation in modern Japan.
\end{abstract}

Keywords. Japan, seasons, lunar calendar, festivals, seasonal celebrations

\section{Introduction}

Historically, even in periods of relative isolation, Japan has assimilated practices and behaviors of other cultures, often using strong indigenous filters to maintain what it sees as a relatively continuous cultural identity bridging antiquity with modern development. The way in which Japan adopted icons, reckoning methods, and practices related to celebrations of seasonally based holidays and festivals provides a particularly interesting study in how one culture may incorporate and modify the astronomically related practices of another to construct a cultural astronomy reflecting values it perceives to be uniquely its own. This article explores this process by looking at: (1) early and later Chinese astronomical bases of seasonal determination and celebration; (2) evolving adaptations of icons and practices in celebration within Japan based on specific cultural values, needs, and experiences with specific attention to the example of Tanabata; (3) changes in calendar reckoning and dates of celebration due to modernization and adoption of 'Western' methods; and (4) relative changes in observation of holidays and festivals, awareness of astronomical associations, and maintenance of cultural values in modern Japan.

\section{Astronomical bases of seasonal celebration}

It is important to be aware of the basic positions of sun and moon relative to seasonal markers (often referred to as solar terms) in order to understand the milieu in which astronomical knowledge and calendar reckoning methods were introduced into Japan in the early centuries of the common era. ${ }^{1}$ Specific principal terms (including solstices and

1 Much of what is known about astronomical knowledge in Asia during periods both before and during influx into Japan comes from broader scholarship in the study of Chinese and Korean science and astronomy. A full review of this body of knowledge is far beyond the scope of this article, but the reader is urged to consult Sun \& Kistemaker (1997) as well as the representative texts Chen (1996) and Cullen (1996). Specific impacts on Japan may be found in the classic Nakayama (1969) and Sugimoto \& Swain (1989). Watanabe (1987) remains an authoritative source in Japanese. 


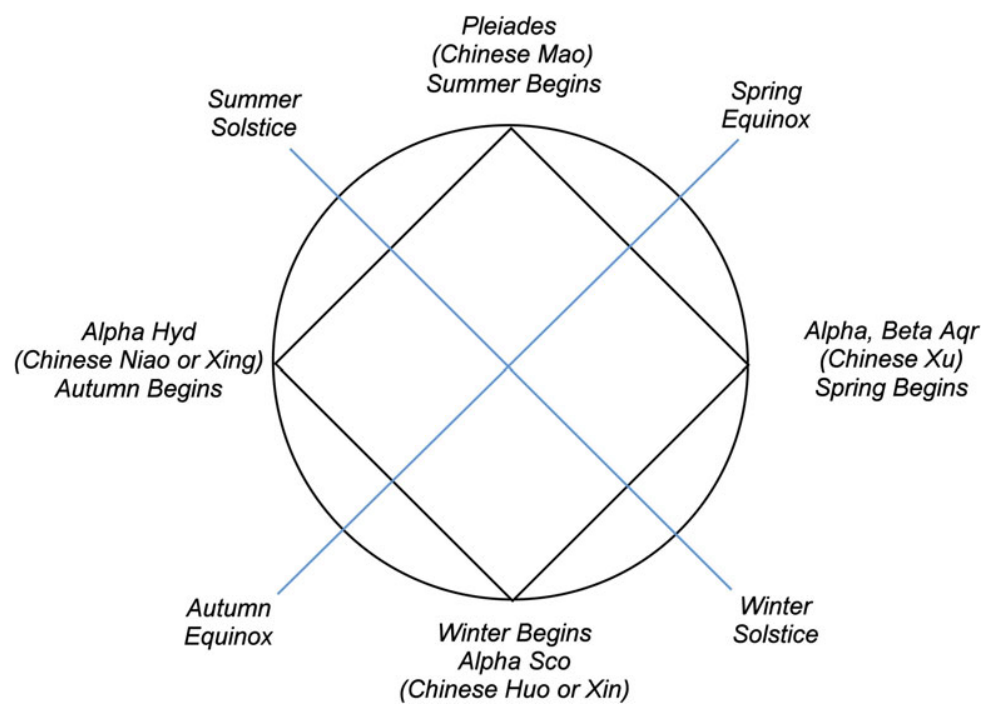

Figure 1. Solstices, equinoxes, and sectional terms around $600 \mathrm{CE}$ relative to the Four Cardinal Asterisms as noted in the Canon of Yao in the Book of Documents. See Sun \& Kistemaker (1997) and Major (1993).

equinoxes) and sectional terms (including civil beginnings of seasons) may be seen in the early developed Chinese view of the Cosmos incorporating a circular heaven and square earth. Briefly, sectional terms of seasonal beginning are midway between equinoxes and solstices. Equinoxes and solstices are 90 degrees from one another as are sectional terms of seasonal beginnings. Appearances of a full moon at any solar term would indicate the sun being in the opposite term. Waxing quarter moons at any term would indicate the sun being at the term 90 degrees westward, and waning quarter moons would indicate the sun at a term 90 degrees eastward. Fig. 1 shows such positions at about $600 \mathrm{CE}$ corresponding to an era of much import of astronomical knowledge, reckoning methodology, and tradition into Japan from the Asian continent. At this time, a full moon in the Pleiades would indicate the sun at sectional term 'Winter Begins'. A waxing quarter moon in Scorpio or a waning quarter moon in the Pleiades would indicate the sun being near the sectional term 'Fall Begins'.

Such juxtapositions were important in the symbolism of seasonally based holidays. In China, festivals and celebrations with lunar based dates were generally established around the civil or astrological seasons (sectional terms), and many seasonal celebrations in Japan were adopted from Chinese counterparts. Still a fundamental part of modern Japanese culture, these holidays and festivals were and are related to: (1) 'Spring Begins' (February 4), including the lunar New Year and associated Setsubun; (2) 'Summer Begins' (May 6), including a series of holidays falling within what is now known as Golden Week; (3) and 'Fall Begins' (August 8), including Tanabata and Bon in what is now known as Silver Week.

Some holidays and festivals, such as the New Year (first day of the first month and on average falling about Feb 4) and Tanabata (seventh day of the seventh month and falling on average about Aug 8), were lunar based and celebrated on different days each year relative to the given solar sectional term. Others, such as Setsubun (Feb 3 and often termed 'New Years Eve'), were solar based and celebrated near or on the sectional term itself. Traditional celebrations were usually associated not only with position of sun and 
moon but often other stellar configurations observed in the season (as illustrated in the later example of Tanabata). ${ }^{2}$

\section{Japanese values and adaptations of icons and practices}

Japanese culture was significantly affected by its wide adoption of many aspects of Chinese culture, most noticeable perhaps in various interactions in the 7 th- 9 th centuries. However, adoption did not necessarily mean wholesale assimilation of all values and logic underlying these imports. Japan was somewhat slow in the adaptation of mathematical astronomy and precise calendar reckoning methods from the very beginning of the process of importation (Sugimoto \& Swain 1989; Nakayama 1969). Over the centuries, icons and practices reflecting what were seen as unique Japanese cultural values and behaviors became associated with virtually all seasonal holidays and festivals. Both initially and in later centuries, methods of lunar reckoning often differed significantly from those in China. Japan's assimilation of Chinese culture was often that of accepting its form rather than its content (Nakayama 1969), and these forms were often used as a basis for political hegemony as well as incorporation of values perceived to be unique to the culture.

In the early development of the Japanese state, primary purposes included unification and subjugation of disparate groups throughout the islands, and this was often done by incorporating local myth and legend related to seasonal change. Imported stories, festivals, and holidays were imbued with values and practices that could be perceived as unique to the pragmatics of the emerging state (Ooms 2009). Many of these goals related to developing cooperative behavior among the populace relative to planting and harvesting (rice in particular) and in establishing a singular lineal order of imperial rule (Kidder 1993; Brown 1993a). The primary aspects of early Japanese consciousness are linealism, vitalism, and optimism (Brown 1993b; Renshaw \& Ihara 2000). Linealism emphasizes ancestral descendancy with filial duty to parents, siblings, friends, nation, etc. Vitalism emphasizes life along with the abhorrence of anything that has to do with death and stresses ritualistic (not moralistic) purity. Optimism places emphasis on being concerned, not so much with the distant past or future, but rather with moving forward through seasons and cycles of life, regardless of circumstances.

\section{The example of Tanabata}

The celebration of the festival of the weaving maiden or Tanabata provides a particularly good example of how an imported Chinese festival has been adapted over the centuries to incorporate various Japanese political and cultural values. Its celebration in Japan also illustrates how such cultural symbolism can become more important to societal practice than calendrical or astronomical accuracy.

The origins of Tanabata are obscure and complex but apparently related to seasonal change and the beginning of fall (Nojiri 1973, 1988 ${ }^{3}$ ). In modern China, it is often termed 'Chinese Valentines Day' but what may have been strong symbolism of traditional cultural values in that culture seems to have been lost. The story and associated festival were probably imported from China into Japan in the Heian Era (794-1185). There are noticeable adaptations of the Chinese version based on aforementioned values and needs

${ }^{2}$ For more details regarding the development of lunar calendars both in China and in Japan, see Nakayama (1969). See also articles on calendars and festivals in Japan in Campbell \& Noble (1993) and Okada \& Akune (1993).

${ }^{3}$ For an English version and explanation, primarily of the Chinese version, see Krupp (1991). 
of Japanese culture. In Japan, the star Vega is often called Orihime Boshi (Weaving Princess Star), and Altair is often called Kengyuu Boshi or Hiko Boshi (Puller of Cows Star). The following is a paraphrased translation of Hara's (1975) Japanese version of the tale (see also Renshaw \& Ihara 2000):

One day, the emperor's daughter, Orihime, was sitting beside the Milky Way. She had been weaving because her father, the emperor, 'wished it' (he loved the beautiful clothes that she made). On this day, she was very sad because she realized that she had been so busy that she didn't have time to fall in love. Her father, Tentei, the ruler of the heavens, felt sorry for her and arranged a marriage with Kengyuu (who lived across the river, the Milky Way). Their marriage was one of sweetness and happiness from the start; and everyday thereafter they grew happier and happier. But Tentei became very angry, because in spending so much time in her happy marriage, Orihime was neglecting her weaving. Tentei decided to separate the couple, so he placed them back in their original places, separated by the Milky Way. On only one night of the year would he allow them to meet, the seventh day of the seventh month. Every year on that day, from the mouth of the river (the Milky Way), the boatman (of the moon) comes to ferry Orihime over to her beloved Kengyuu. But if Orihime has not done her weaving to the best of her skills and ability, Tentei may make it rain. When it rains, the boatman will not come (because the river is flooded). However, in such a case, Kasasagi (a group of magpies) may still fly to the Milky Way to make a bridge for Orihime to cross.

Early Japanese adopters of the legend celebrated the festival of Tanabata on the seventh day of the seventh month each year (lunar calendar). As mentioned, this date on average falls about the sectional term 'Fall Begins' on August 8. Fig. 2 provides a view of the Tanabata sky as it appears at this time in 2011. Though somewhat different owing to precession from more ancient views, the associated symbolism is still readily observed. The seventh day of the seventh month finds a waxing crescent moon (boat) reaching its first quarter. The seasonal marker of Antares in the center of the azure dragon is of course prominent. Orihime Boshi (Vega) and Kengyuu Boshi (Altair) are quite conspicuous and separated by the Milky Way. A view to the north would find the handle of the Big Dipper turning to point to the west or fall. Other seasonal symbols of Chinese origin, such as the southern dipper in Sagittarius (see Chen 1996; Cullen 1996), are easily observed.

When it was first imported, Tanabata was celebrated only by imperial court officials. In time, the festival took on more of the values inherent in Japanese consciousness and purpose (Nojiri 1988). Tanabata may be translated as 'weaving with the loom (bata) placed on the shelf (tana)', and the festival in Japan still incorporates values of improvement in technical skill and ability. Its adapted form has emphasized the need for hard work and cooperative effort in the coming harvest, and modern celebrations still maintain such values in a more corporate context. The myth has always held seasonal significance with a desire for no rain (as necessary for successful harvest). Throughout the centuries, it has also been adapted to incorporate virtually all the aforementioned ancient and modern values of the culture.

A particularly interesting example of such adaptation may be seen in the decorated Tanabata strip from the Tottori Region shown in Fig. 3. Here, several three star configurations or Mitsu Boshi are found. Such configurations are often termed Oyakoukou Boshi and imply a kind of filial duty one has to one's parents, thus incorporating a strong sense of linealism, optimism, and vitality. Incorporated in stellar configurations in various constellations (such as the belt stars of Orion) and quite noticeable in several representations appearing at Tanabata, the three star configurations illustrate the child holding up his/her parents or the three (parents and child) standing together. This familial and lineal symbol of 'three' is found in many legends of Japan, and is apparently 


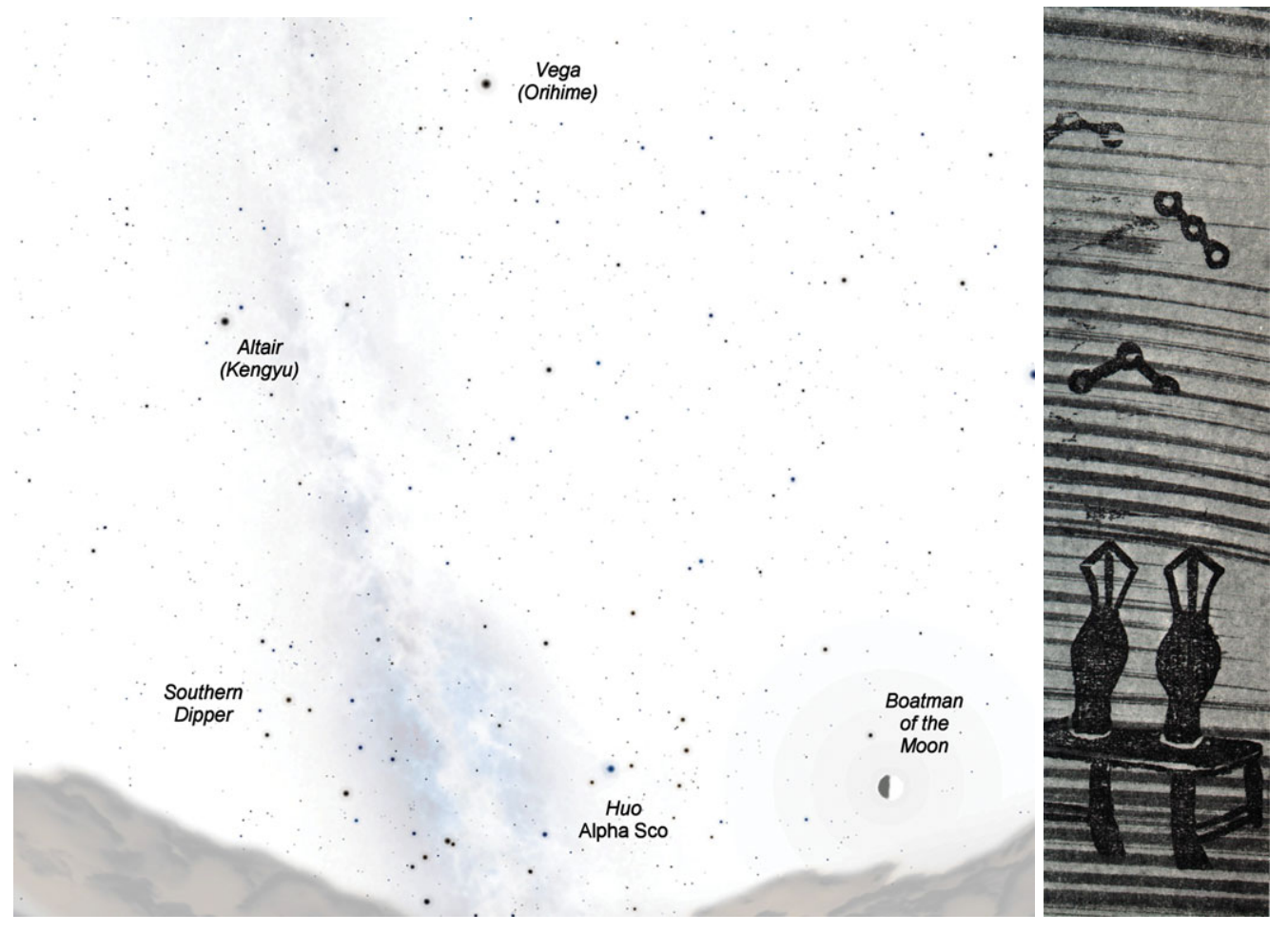

Figure 2. (Left) Simulated Sky Configuration for Tanabata in 2011. The lunar seventh day of the seventh month occurs on August 6 in 2011, two days before the sectional term 'Fall Begins'. Significant constellations of the legend as well as agricultural significance and cultural values of filial piety are noted. Fundamental simulation was generated with Starry Night Pro Plus 6 (Version 6.3.9).

Figure 3. (Right) Decorated Strip of Tanabata Bamboo from the Tottori Region of Japan. Note the representation of Oyakoukou Boshi representing filial piety. These may represent $\alpha$ Lyr (Vega) (Orihime) apparently flanked by $\epsilon(1,2)$ and $\zeta$ Lyr, and $\alpha$ Aql (Kengyu) apparently flanked by $\beta$ and $\gamma$ Aql. It is possible that $\alpha$ Sco (Huo-Xin) flanked by $\tau$ and $\sigma$ Sco are represented carrying the same symbolic meaning. From Nojiri (1973: 60) by kind permission of the publisher.

incorporated in the strong sense of Japanese consciousness implanted in the cultural celebration of Tanabata.

The process of adapting this imported legend and indigenous practice evolved in complex ways over the centuries. In modern times, the festival is generally celebrated on (a solar) July 7 th, a date that is generally still within the rainy season.

\section{Calendar change and Western adaptation}

Recognition of accumulating errors in the lunar calendar and the opening of Japan following the Meiji Reformation of the mid-19th century brought further cultural exchange and adoption of a 'Western' calendar for determining dates of holidays and festivals. While leaving basic cultural values intact, the ensuing confusion related to changes in dates which had been based on lunar reckoning appears to have had an impact not only on celebration practices but also meaning and significance. Sukehiro (1993: 471) has written: 
"The actual use of the solar calendar after its adoption in $1872 \ldots$ was not particularly rapid or widespread. The traditional lunar-solar 'Tempou Calendar', intricately connected with the pulse of agricultural seasons, suited the Japanese life pattern well. For a time, the Meiji calendar was dubbed the 'imperial court calendar' as opposed to the 'Tokugawa calendar' to which people were accustomed. Not until 1911 were the lunar listings of days removed from the calendars, and even today many Japanese feel certain nostalgia for the old lunar calendar."

Numerical names for months that had been used in the lunar calendar were used for names of months in the 'Western' calendar, and many lunar dates were simply changed to their solar counterpart. The Gregorian 'New Year' was adopted and consequently detached from 'Spring Begins', thus trivializing association with the still celebrated Setsubun. Tanabata, related to the beginning of fall and observed on the seventh day of a lunar seventh month, was changed (with some local exceptions) to the seventh of July, a date which might or might not have a waxing moon at first quarter and which would fail to reflect both astronomically associated phenomena and seasonally related behavior such as harvesting.

\section{Modern celebration and considerations}

While many cultural values associated with holidays and festivals have been maintained, a century and a half of emergence as an industrial society with international trade aims has led to more emphasis on the pragmatic aspects of celebration (such as work and transportation flow) and less on the astronomical phenomena and seasonal significance on which many holidays and festivals were originally based, even those celebrated near dates of solar terms. Few Japanese now have a conception of Setsubun as an 'eve' of the New Year or the relation of Tanabata and Bon to the beginning of fall and harvest. It has even been suggested that to aid airport, rail, and highway congestion, festivals of Golden Week and Silver Week be spread over two- to three-week periods with staggered celebration dates differing by regions of the country (Otake 2010). Integral astronomical aspects of seasonal festivals seem to have been lost.

As mentioned, in most of Japan Tanabata is now celebrated on a solar July seventh. At such time, rice is certainly not ready for harvest, and where it is planted, farmers are generally hoping for rain rather than lack thereof. Obviously, in such solar reckoning, the position of the moon signifies little or 'nothing'. North of Tokyo, the city of Sendai is noted for its celebration of Tanabata on August 7 on the 'eve' of 'Autumn Begins'. This is perhaps an ironic compromise both of number and season. Such celebration may be agriculturally appropriate, but the position of the moon on this solar calendar date again signifies little or 'nothing'.

Apart from agrarian needs, specific astronomical bases of holidays and festivals may never have been a major concern of ordinary Japanese citizens. Rather, values and aesthetics perceived to be indigenous and fundamental to the culture may have evolved to be the primary focus of seasonal celebration. A tremendous amount of art, poetry, and lore has arisen in Japan over the centuries related to associations of the sun, moon, and stars with various events and values of the culture. Despite what may seem to be an inconsistent and even irrational determination of dates for celebration, basic Japanese values such as recognition of the necessity of increased diligence in work associated with Tanabata (regardless of whether or not fall and harvest have begun) or respect for ancestors at Bon (celebrated around August 15th and usually with no full moon, but now with strong associations related to the closing events of World War II) are a fundamental part of modern celebratory practice. Astronomical phenomena that once formed the 
basis of cultural projection in the development of seasonal holidays and festivals may have lost their original significance, but it can easily be argued that iconography and practice based on adaptation of this cultural astronomy has acted and continues to act as a fundamental vehicle for transmission of cultural values from generation to generation in Japan.

\section{Acknowledgements}

The author would like to express great appreciation to Saori Ihara for aid in translation of Japanese materials.

\section{References}

Brown, D. M. 1993a, The Yamato kingdom. In D.M. Brown (ed.), The Cambridge History of Japan, Vol. 1, Ancient Japan, Cambridge University Press, Cambridge, pp. 108-162.

Brown, D. M. 1993b, The early evolution of historical consciousness. In D.M. Brown (ed.), The Cambridge History of Japan, Vol. 1, Ancient Japan, Cambridge University Press, Cambridge, pp. 504-577.

Campbell, A. \& Noble, D. S. 1993, Japan: an Illustrated Encyclopedia, Kodansha, Tokyo.

Chen C-Y. 1996, Early Chinese Work in Natural Science: a Re-examination of the Physics of Motion, Acoustics, Astronomy and Scientific Thoughts, Hong Kong University Press, Hong Kong.

Cullen, C. 1996, Astronomy and Mathematics in Ancient China: the Zhou bi Suan Jing, Cambridge University Press, New York.

Hara, M. 1975, Seiza no Shinwa (Mythology of the Constellations), Kouseisha Co. Ltd, Tokyo.

Kidder, J. E. 1993, The earliest societies in Japan. In D.M. Brown (ed.), The Cambridge History of Japan, Vol. 1, Ancient Japan, Cambridge University Press, Cambridge, pp. 48-107.

Krupp, E. C. 1991, Beyond the Blue Horizon: Myths and Legends of the Sun, Moon, Stars, and Planets, Oxford University Press, New York.

Major, J. S. 1993, Heaven and Earth in Early Han Thought: Chapters Three, Four, and Five of the Huainanzi, State University of New York Press, Albany.

Nakayama, S., 1969, A History of Japanese Astronomy: Chinese Background and Western Impact, Harvard University Press, Cambridge MA.

Nojiri, H. 1973, Seimei Jiten (Dictionary of Star Names in Japan), Tokyo Do Shuppan, Tokyo.

Nojiri, H. 1988, Hoshi no Shinwa Densetsu Shusei (Collection of Mythology and Star Legends), Koseisha Koseikaku, Tokyo.

Okada, Y. \& Akune, S. 1993, Gendai Koyomi Yomikaki Jiten (Modern Calendar Dictionary), Kashiwa Shoubou, Tokyo.

Ooms, H. 2009, Imperial Politics and Symbolics in Ancient Japan, University of Hawaii Press, Honolulu.

Otake, T. 2010, Moves afoot to make Japanese holidays a pleasure not a pain. Japan Times, Tokyo, 2010 March 21.

Renshaw, S. \& Ihara, S. 2000, A cultural history of astronomy in Japan. In H. Selin (ed.), Astronomy across Cultures: the History of Non-western Astronomy, Kluwer, Dordrecht, pp. $385-407$.

Sugimoto, M. \& Swain, D. L. 1989, Science and Culture in Traditional Japan, Charles E. Tuttle, Tokyo.

Sukehiro, H. 1993, Japan's turn to the West. In M.B. Jansen (ed.), The Cambridge History of Japan, Vol. 5, The Nineteenth Century, Cambridge University Press, Cambridge, pp. 432-498.

Sun X. \& Kistemaker, J. 1997, The Chinese Sky during the Han: Constellating Stars and Society, Brill, New York.

Watanabe, T. 1987, Kinsei Nihon Tenmon Gakushi (A View of Japanese History of Astronomy in Early Modern Times) (2 vols), Koseisha Kosaikaku, Tokyo. 